\title{
Combining Fuzzy AHP with GIS and Decision Rules for Industrial Site Selection
}

\author{
Aissa Taibi* and Baghdad Atmani \\ Laboratoire d'Informatique d'Oran (LIO), University of Oran1 Ahmed Ben Bella, BP 1524 EL \\ Mnaouer Oran (Algeria)
}

Received 13 April | Accepted 9 June 2017 | Published 30 June 2017

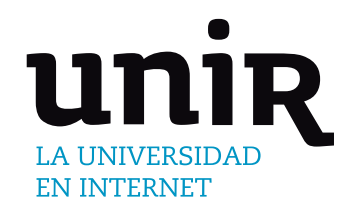

\section{KEYWORDS}

Geographic Information Systems (GIS), MultiCriteria Decision Analysis (MCDA), Industrial Site Selection, MCDA-GIS Integration, Fuzzy Analytic Hierarchy Process (FAHP), Decision Rules.

DOI: $10.9781 /$ ijimai.2017.06.001

\section{INTRODUCTION}

CITE selection is the process of finding the suitable sites for a project $\checkmark$ establishment depending on socioeconomic and environmental criteria [1]. Author in [2] identifies some determining factors in project management literature: 1) The complexity of projects does not depend only on the industry; 2) Project development is not just the realm of the project managers and their team, but there is an important role of stakeholders to play; 3) Uncertainty and continuous change in projects creates a difficulty to plan, and accomplish schedules, resources and budgets. This study takes these factors into account with others for selecting industrial sites and shows that a well measured location reduces the project complexity.

Issues related to the field are problems of zonal aptitudes in the context of decision support. Complexity in decision making for selecting industrial sites derives from the inherent trade-offs between socioeconomic, technical and environmental criteria. Chaotic location causes epidemics and attacks on the health of the citizens. The linear model of Simon (intelligence, design and choice) and its extensions are insufficient to deal with the problem complexity [3].

Each zone is a spatial action only if it is defined by its geographical position, shape and spatial relations [4]. Majority of criteria and all actions of the problem under study have a geographical character. We adopt the approach of coupling between GIS and MCDA methods as the latter is favored by this problem.

The conceptual idea beyond MCDA-GIS integration approach is

* Corresponding author.

E-mail address: taibiissa@yahoo.fr twofold: on the one hand, it is to use the functions of GIS to prepare geographic data necessary in inputs for the MCDA methods, and on the other; it is to employ GIS visualization potentialities to map the analysis results [5].

Geographic information systems (GIS) are needed to model, store, manage, view, analyze, and represent objects or collection of spatial objects. Action assessments according to geographic criteria are based on the most important feature of GIS: Mapping. A map is a model of the reality privileging the geometrical representation of objects with a graphic and semiotic logic [6]. For example the seismic value of an industrial zone derives from its geographical position on the seismic map.

Analytic hierarchy process (AHP) is a popular method used as a tool for multi-criteria decision making (MCDM) or as a weight estimation technique. AHP is used in many areas such as site selection, territory planning, new energy, and so on [7]. AHP allows the solution of problems with geographic nature or GIS-based [8]. This method has mathematical properties and allows total ranking, it requires a hierarchy of the decision problem and a pairwise comparisons of entities in every node of the hierarchy [9].It is remarkable that integrated AHPs are better than the stand-alone AHP [10].

This paper aims to provide decision makers with a ranking model for industrial site selection based on GIS-FAHP integration. For this model to be more efficient in supporting decision making we propose:

1. A mixed integration mode between GIS and AHP to give more flexibility to take into account the geographical character of the data.

2. A set of decision rules is modeled and used as a filter for criteria in input for the AHP method.

3. To deal with fuzziness and uncertainty, we adopt the Chang fuzzy extension [11] of AHP (FAHP) which is based on Fuzzy numbers 
with triangular membership functions.

The remainder of this article is presented as follows: Section 2 and 3 are devoted to related work and background, the proposed approach and proposed Spatial Decision Support System (SDSS) architecture are in sections 4 and 5 , a case study is illustrated in section 6 , we end with a conclusion and perspectives.

\section{RELATED WORK}

Spatial decision problems give rise to the GIS-based multi-criteria decision approach. Author in [12] underlines that in the context of the synergistic capabilities of both GIS and MCDA that theoretical and applied research on GIS-MCDA advances. In this section, we present some works on the theoretical aspects of the approach as well as some applications and we finish by our proposal.

\section{A. Theoretical Research}

The earlier works on this approach, according to [12] are that of Diamond and Wright (1988), Janssen and Reitveld (1990), Carver (1991), Langevin et al (1991).

Among the 363 articles inventoried since 1990 until 2004 in [12], there are $34(9.4 \%)$ that uses AHP and $47 \%$ uses vector mode for geographical representation. Author in [13] develop a Decision Making Support System (DMSS) for land reform in South Africa, he gives new article statistics since 1990 up to 2015 showing the increase in using the GIS-MCDA integration approach. Author in [14] investigates on the motivation behind the approach and interrogates: What this integration is exactly needed for, and if it is really interesting to invest labor in the development of such solutions. In [15] F.Joerin links between land use planning and GIS-MCDA integration and affirms that GIS and MCDA constitute a very interesting package for land management. Author in [5] develops a strategy of GIS-MCDA integration and formulates three integration modes.

\section{B. Applied Research}

Among works using GIS-MCDA approach for industrial site selection we cite:[16], in this work, after declaration that site selection influences the life style of surrounding communities, for this, analysts must strive to determine the optimum location. The proposed approach entails two phases: screening and evaluation, the author integrates three decision tools: Expert system (ES), GIS and MCDA and uses COM (Component Object Model) concept for connecting them, Visual Rule Studio to develop the expert system, ArcGIS 8.2 to provide a GIS platform and Microsoft Excel to provide tools to implement AHP. In [17], following the work cited above, authors value the good selection of an Industrial Site and estimate that $80 \%$ of data used in this field by managers are geographical in nature, they feel that the synergistic effect generated by coupling GIS and MCDA contributes to the efficiency and quality of spatial analysis for industrial site selection, in this work AHP and WLC (Weighted Linear Combination) methods are used.

In the optic of environmental protection, we cite: [18] where the objective is to evaluate the ecological impacts of projects in the context of sustainability assessments. GIS and Analytic Network Process (ANP) are used to identify potential ecological corridors in the Piedmont Region (Northern Italy). In [19] author highlights that environmental research benefits from the integration between GIS and MCDA, he indicates that both MCDA tools and GIS potentialities are needed for spatial multicriteria evaluation, he presents a new GIS-MCDA integration tool for wastewater land application in agriculture. In [20], the author integrates AHP with GIS to locate and rank suitable sites for soil aquifer treatment by considering technical, socio-environmental and cost criteria. In [21] authors attempt to demonstrate how GIS-MCDA integration approach helps to set apart the preferences of regional stakeholders to simplify the decision making process in planning park in Canada.

Another work relating to the energy diversification is to design a model based on GIS-MCDA integration for conducting wind energy project [22]. In [23] risk index and cost are the main criteria used to determine the preferable route of power transmission line (PTL) using conjointly AHP and PROMETHEE, GIS and MCDA are used synergistically to generate the best solution. In [24] authors couple AHP and OWA(Ordered Weighting Averaging) with GIS for mapping accessibility patterns of housing development sites in Cammore Alberta, the proposed system supports housing developers to trade off between benefits and costs to access facilities by residents.

Most works cited above use AHP, which is based on the use of crisp numbers while the modeling of data in decision field requires fuzzy numbers. Since fuzziness is a common characteristic of decision making problems, the FAHP method was developed to address this problem. In [25] author makes a state-of-the-art survey of FAHP, he underlines that 190 research application papers are published between 2004 and 2016 to argue that FAHP has been applied to a wide range of applications. In [26] the author assesses vulnerability to earthquake hazards through spatial multi-criteria analysis of urban areas; he uses FAHP and GIS to treat criteria for social risks, induced risks and systemic vulnerability. In [27] the problem is to select the best location for wastewater lift station by designing a model based on FAHP and GIS. Author in [28] highlights the impact of landfill selection on the environment, economy and ecology, he proposes a two-step solution: (i) use of GIS to determine candidate areas; (ii) use of fuzzy multi criteria decision-making (FAHP) to rank them. In [29] the authors propose a system which integrates fuzzy set theory (FST), factor rating system (FRS) and simple additive weighting (SAW) to evaluate facility locations alternatives. The purpose in [30] and [32] is to protect Turkish lakes by integrating GIS and AHP for landfill site selection. In [31] author focuses on the final disposal as a stage of municipal solid waste (MSW) and uses a fuzzy multi-criteria method to determine the best location. In [33] the authors propose an application of a new hybrid fuzzy AHP Model to locate international distribution trade centers. In the field of site selection for tourist hotels, authors in [34] treat 21 criteria using FAHP and give a clear direction for investors. In [35] there is application of FAHP approach for selecting the best underground mining method in IRAN, taking into consideration decision maker subjectivity. The purpose of the authors in [36] is to select an appropriate location to implant industrial corporation by combining FAHP and On Line Analytical Processing (OLAP) analysis.

In this paper a mixed integration is proposed: indirect integration in screening phase and full integration in the evaluation phase.

After developing the hierarchy for ranking industrial zones in Algeria using AHP, we propose a decrease of this hierarchy by reducing technical criteria with decision rules. In this way we can:

- Reduce the complexity and have more coherence during the construction of pairwise comparison matrixes.

- Use qualitative data with subjective importance required by AHP, technical criteria with objective importance are not necessary.

Linguistic variables and triangular fuzzy numbers [11] are adopted to model the decision maker's (DM) hesitance and subjectivity attitudes. We will describe in detail, our approach and its implementation in section IV and V.

\section{BACKGROUND}

We begin this section by arguing the necessity to use the GISMCDA integration approach to get the best solution for spatial decision problems and then basic concepts of FAHP and decision rules are presented. 


\section{A. GIS-MCDA Integration}

Solution of spatial decision problems means combining and transforming geographical as well as decision data (input) to have a resulting decision (output).

GIS is an excellent tool for acquisition, storage, manipulation and spatial analysis of geographic data, but has a lack to deal with spatial decision problems especially with conflicting objectives in the decision-making process. Below some critics addressed to GIS technology [5].

- Decision data like decision maker's preferences are not taken into account by current GIS.

- Assessment and comparison of different scenarios are not permitted by GIS. The solutions given by GIS satisfy all criteria simultaneously.

- Analytic functionalities found in most GIS are oriented towards the management of data, but not towards an effective analysis of them.

MCDA is a technique to assess and structure actions according to a set of conflicted criteria and a proposed decision maker's preference. MCDA comes to overcome the lack of GIS in tackling spatial decision problems. Salem in [5] underlines the necessity of GIS-MCDA integration and proposes three modes: (1) An indirect GIS-MCDA integration mode; (2) A built-in GIS-MCDA integration mode; (3) A full GIS-MCDA integration mode.

GIS and MCDA are two different areas of research, but they complement each other for solving spatial decision problems.

The conceptual idea on which GIS-MCDA integration is based is to use the capabilities of GIS to prepare inputs necessary for multicriteria method and exploit the potential of GIS for results visualization.

\section{B. AHP and its Fuzzy Extension}

AHP has been studied extensively and used in almost all the applications related with MCDA in the last 20 years [37]. AHP has the flexibility to combine quantitative and qualitative data, to handle different groups of actors, to combine the opinions expressed by many experts, and can help in stakeholder analysis [38]. AHP is based on the additive weighting model and can be used in GIS environment in the same way that the WAC (Weighted Additive Combination) method.

Defect in original AHP is the use of crisp numbers, while uncertainty and vagueness of the experts' opinion are the prominent characteristic of decision making problems. FAHP is developed to address this problem and overcomes this defect. In applications it is often convenient to work with Triangular Fuzzy Numbers (TFNs) because of their computational simplicity, and they are useful in promoting representation and information processing in a fuzzy environment. In addition, TFNs are the most utilized in FAHP studies [39]. Linguistic variables and triangular fuzzy numbers are used to model the decision maker's (DM) hesitance and subjectivity attitudes when constructing pairwise comparison matrixes [11]. This paper adopts TFNs in the FAHP and describes their algebraic.

A TFN can be defined by a triplet $(1, \mathrm{~m}, \mathrm{u})$ and the membership function $\mu_{M}(x)$ is illustrated in Fig. 1 and defined in equation (1) [39]:

$$
\mu_{M}(x)=\left\{\begin{array}{cl}
0 & \text { si } x<l \\
\frac{x-l}{m-l} \quad & \text { si } l \leq x \leq m \\
\frac{h-x}{h-m} & \text { si } m \leq x \leq h \\
0 & \text { si } x \geq h
\end{array}\right.
$$

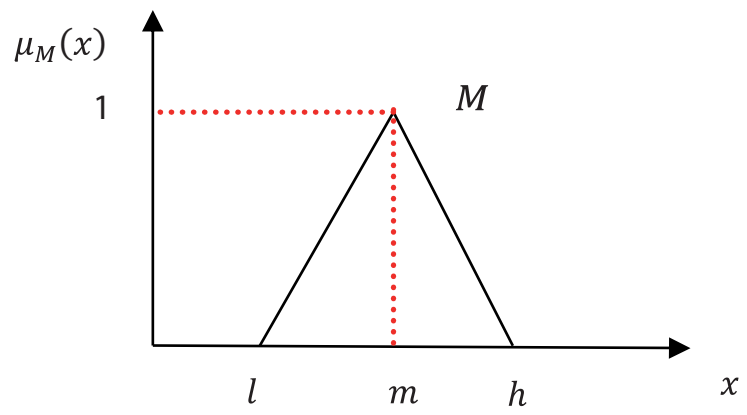

Fig. 1. Fuzzy triangular function.

There are various operations on TFNs; four operations used in this paper are illustrated.

Let two TFNs A and $\mathrm{B}$ be defined by the triplets:

$A=(a, b, c)$ and $B=(d, e, f)$.

Then:

$$
\begin{gathered}
A \oplus B=(a, b, c) \oplus(d, e, f)=(a+d, b+e, c+f) \\
A \Theta B=(a, b, c) \Theta(d, e, f)=(a-d, b-e, c-f) \\
A \otimes B=(a, b, c) \otimes(d, e, f)=(a . d, b . e, c . f) \\
A / B=(a, b, c) /(d, e, f)=\left(\frac{a}{d}, \frac{b}{e}, \frac{c}{f}\right)
\end{gathered}
$$

The two sets:

$\mathrm{X}=\left\{\mathrm{x}_{1}, \mathrm{x}_{2}, \mathrm{x}_{3}, \ldots, \mathrm{x}_{\mathrm{n}}\right\}$ as an object set, and

$\mathrm{G}=\left\{\mathrm{u}_{1}, \mathrm{u}_{2}, \mathrm{u}_{3} \ldots, \mathrm{u}_{\mathrm{m}}\right\}$ as a goal set. According to the principles of Chang's extent analysis [44], each object is considered correspondingly and extensive analysis for each of the goals, $\mathrm{g}_{\mathrm{i}}$ is executed. It means that $m$ extent analysis values for each object can be obtained using the following signs:

$$
M_{g_{i}}^{1}, M_{g_{i}}^{2}, \ldots M_{g_{i}}^{m} \quad i=1,2, \ldots, 3
$$

Where $M_{g_{i}}^{j} j=1 \ldots m$ are triangular fuzzy numbers and:

The value of fuzzy synthetic extent with respect to the $i^{\text {th }}$ object is represented as:

$$
S_{i}=\sum_{j=1}^{m} M_{g_{i}}^{j} \otimes\left[\sum_{i=1}^{n} \sum_{j=1}^{m} M_{g_{i}}^{j}\right]^{-1}
$$

The fuzzy addition operation of $\mathrm{m}$ extent analysis values must be performed for particular matrix to obtain $\sum_{j=1}^{m} M_{g_{i}}^{j}$ such that:

$$
\sum_{j=1}^{m} M_{g_{i}}^{j}=\left(\sum_{j=1}^{m} l_{j}, \sum_{j=1}^{m} m_{j}, \sum_{j=1}^{m} h_{j}\right)
$$

Then, we perform the fuzzy edition operation of $m$ extent analysis values for a particular matrix to obtain

$$
\sum_{i=1}^{n} \sum_{j=1}^{m} M_{g_{i}}^{j}=\left(\sum_{i=1}^{n} l_{i}, \sum_{i=1}^{n} m_{i}, \sum_{i=1}^{n} h_{i}\right)
$$

And the inverse of the vector in Eq. (3) is computed such that

$$
\left[\sum_{i=1}^{n} \sum_{j=1}^{m} M_{g_{i}}^{j}\right]^{-1}=\left(\frac{1}{\sum_{i=1}^{n} h_{i}}, \frac{1}{\sum_{i=1}^{n} m_{i}}, \frac{1}{\sum_{i=1}^{n} l_{i}}\right)
$$

\section{Decision Rules}

The kind of preferential information modeled by decision rules seems to be close to the natural reasoning. This type of rules can be used alone to tackle decision problem. In [40] author presents an approach called Dominance based Rough Set Approach (DRSA) based on decision rules and dominance principle for decision support. Author in [5] proposes a model based on rules for choosing the appropriate method 
according to the proposed problem. The rules cover three categories of facts: i) the characteristics of spatial decision-making problem, ii) the characteristics of decision makers and iii) characteristics of the method itself. The simplicity in modeling by rules, facilitate for experts to formulate knowledge. Author in [41] develops and implements a rule base for selection of landfill sites in Switzerland; he raised practically the problem of explosion in the number of rules needed for this specific case (for 10 criteria there are 310 combinations). To find weights of deducted criteria (criteria in conclusion) he adds the weights of basic criteria (criteria in premises) without returning to the decision maker.

It seems advantageous to combine the MCDA techniques with rule base. The rule base serves as a filter that performs a pre-treatment of information and consequently reduces the amount of data to be processed by MCDA.

\section{PROPOSED APPROACH}

In this section, we present the main aspect of our contribution. As mentioned in the previous section, Salem in [5] proposes three integration modes, indirect integration, built-in integration and full integration. In this paper a mixed integration is proposed: Preparing geographic criteria to support decision making in weighting is made by GIS independently (indirect integration) in screening phase while visualization function is integrated directly (full integration) in the MCDA module in the evaluation phase and is considered as a finality of the decision analysis (Fig. 2).

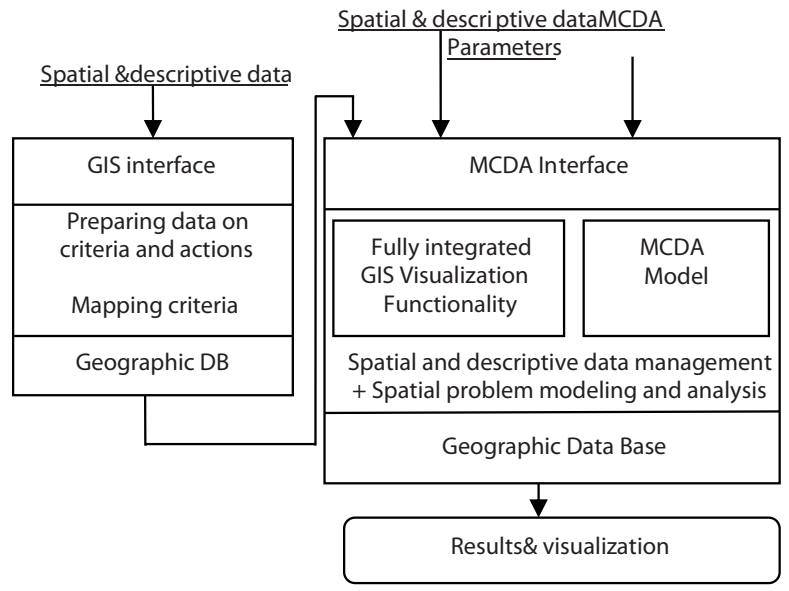

Fig. 2. GIS-MCDA proposed integration mode.

The proposed approach consists of two phases: Screening and evaluation as explained below and depicted in (Fig. 3)

- Screening phase: After the choice of zones at the beginning of the decision-making process, zones studies begins by collecting data about criteria and actions from geographic, socioeconomic and climate databases as archives of regions, the maps for the criteria are built using GIS. A field of expertise is available. A rule base is constructed in order to reduce the number of criteria before decision analysis.

- Site evaluation phase: consists of the total ranking by combining FAHP and a specific rule base. The AHP procedure involves six essential steps [9, 42]:

1. Definition of the problem

2. Represent the problem by an hierarchy structure

3. Construct pairwise comparison matrixes

4. Estimate the relative weights

5. Check the consistency

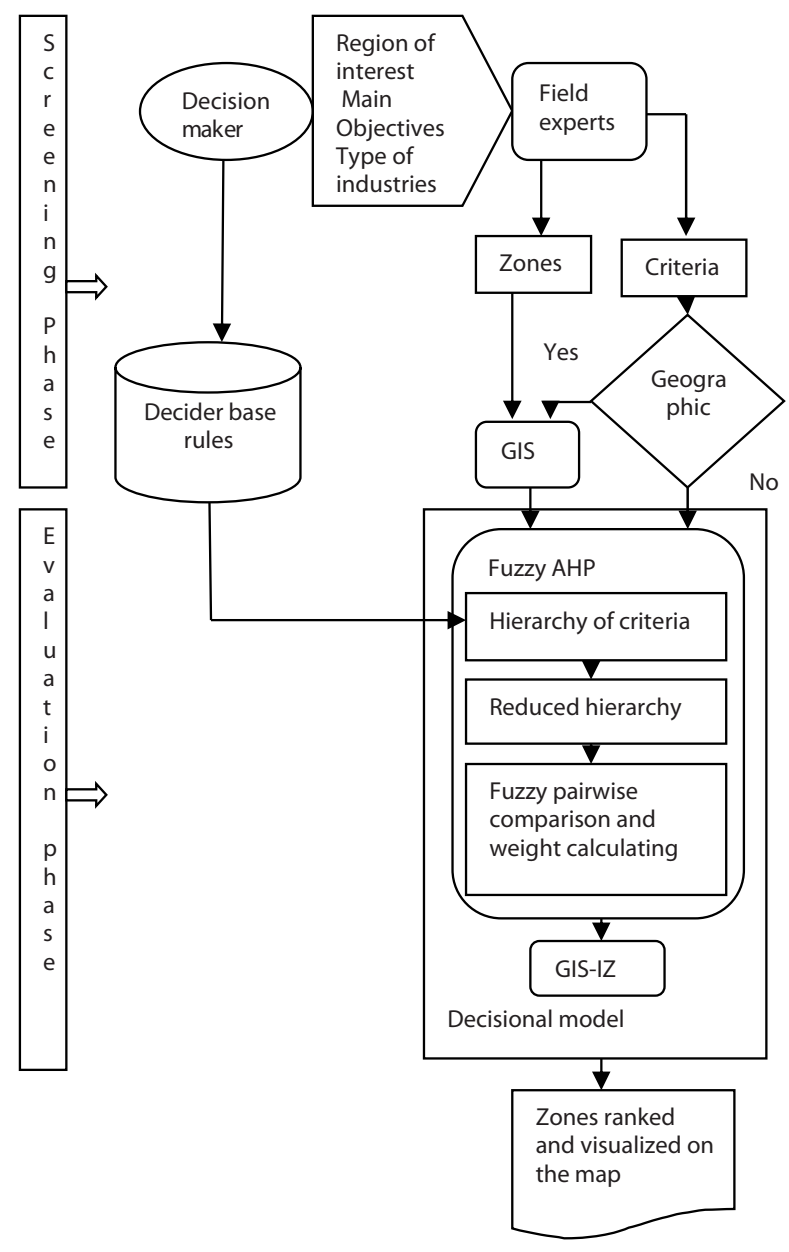

Fig. 3. Framework of Proposed Approach.

6. Obtain the overall rating

After developing hierarchy for a specific problem, we propose a reduction of technical criteria by using decision rules. The objective is to give more flexibility for studying geographical criteria and mapping alternatives. These rules are modeled and used as a filter for criteria in input, which allows a considerable reduction of the problem hierarchy. The purpose is to reduce the technical criteria into reduced ones with subjective importance, it is to be noted that AHP is a subjective methodology (Fig. 4). Thus a step named "Reducing the problem hierarchy" is added after step2.

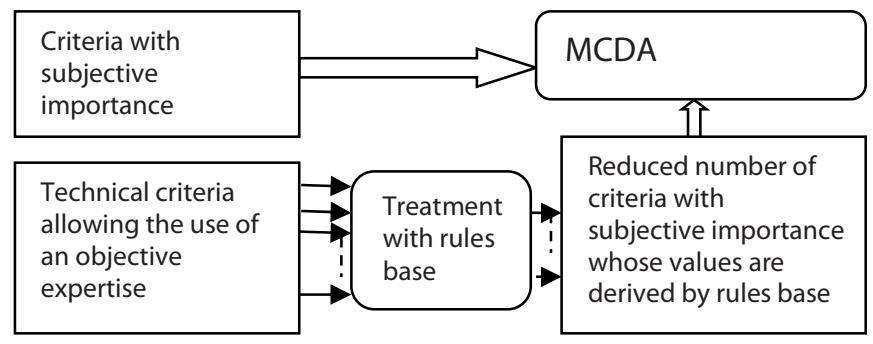

Fig. 4. Combining multi-criteria analysis and rule base inspired from [43].

To deal with uncertainty and decision maker hesitation in pairwise comparison (Step 3) there are many fuzzy-AHP methods proposed by various authors (Buckley, 1985; Chang, 1996; Cheng, 1997; Deng, 1999; Leung and Cao, 2000; Mikhailov, 2004; VanLaarhoven and Pedrycz, 1983). Chang Fuzzy AHP extension [11] as explained in subsection (III, A) is conforming to this study. 
Decision maker gives his pairwise comparison matrixes according to Saaty9-unit scale as shown in Table I [9].

table I. Scale of Relative Preference Based on Saaty [9]

\begin{tabular}{cc}
\hline $\begin{array}{c}\text { Intensity of preferences } \\
\text { Numerical value }\end{array}$ & $\begin{array}{c}\text { Definition } \\
\text { (Verbal Scale) }\end{array}$ \\
\hline 1 & Equally preferred \\
3 & Weak preference of one over other \\
5 & Strongly preferred \\
7 & Very strongly preferred \\
9 & Extremely preferred \\
$2,4,6,8$ & Intermediate values between the two \\
\hline \hline
\end{tabular}

The result matrixes of the pairwise comparisons made by Decision Maker are transformed into Fuzzy ones by means of linguistic variables, represented by triangular fuzzy numbers listed in Table II.

Extent analysis method (in subsection III, A) is used to evaluate the importance weight and consequently the rank of each action (Industrial zone).
TABLE II. Triangular Fuzzy Numbers for Pairwise Comparisons

\begin{tabular}{ccc}
\hline \hline Linguistic variables & TFNs & Reciprocal TFNs \\
\hline Extreme strongly preferred & $(7,9,9)$ & $(1 / 7,1 / 9,1 / 9)$ \\
Intermediate & $(6,8,9)$ & $(1 / 6,1 / 8,1 / 9)$ \\
Very strongly preferred & $(5,7,9)$ & $(1 / 5,1 / 7,1 / 9)$ \\
Intermediate & $(4,6,8)$ & $(1 / 4,1.6,1 / 8)$ \\
Strongly preferred & $(3,5,7)$ & $(1 / 3,1 / 5,1 / 7)$ \\
Intermediate & $(2,4,6)$ & $(1 / 2,1 / 4,1 / 6)$ \\
Moderately preferred & $(1,3,5)$ & $(1,1 / 3,1 / 5)$ \\
Intermediate & $(1,2,4)$ & $(1,1 / 2,1 / 4)$ \\
Equally preferred & $(1,1,1)$ & $(1,1,1)$ \\
\hline \hline
\end{tabular}

\section{Proposed Spatial Decision Support System (SDSS)}

Inspired from the general Decision Making Support System Architecture in [43], taking into account the geographical aspect of data, the proposed DMSS has the architecture shown in Fig. 5.
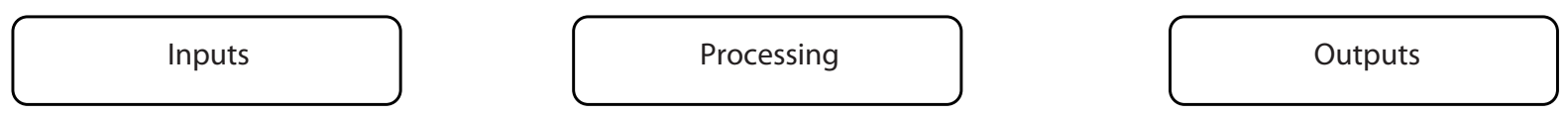

Input feedback

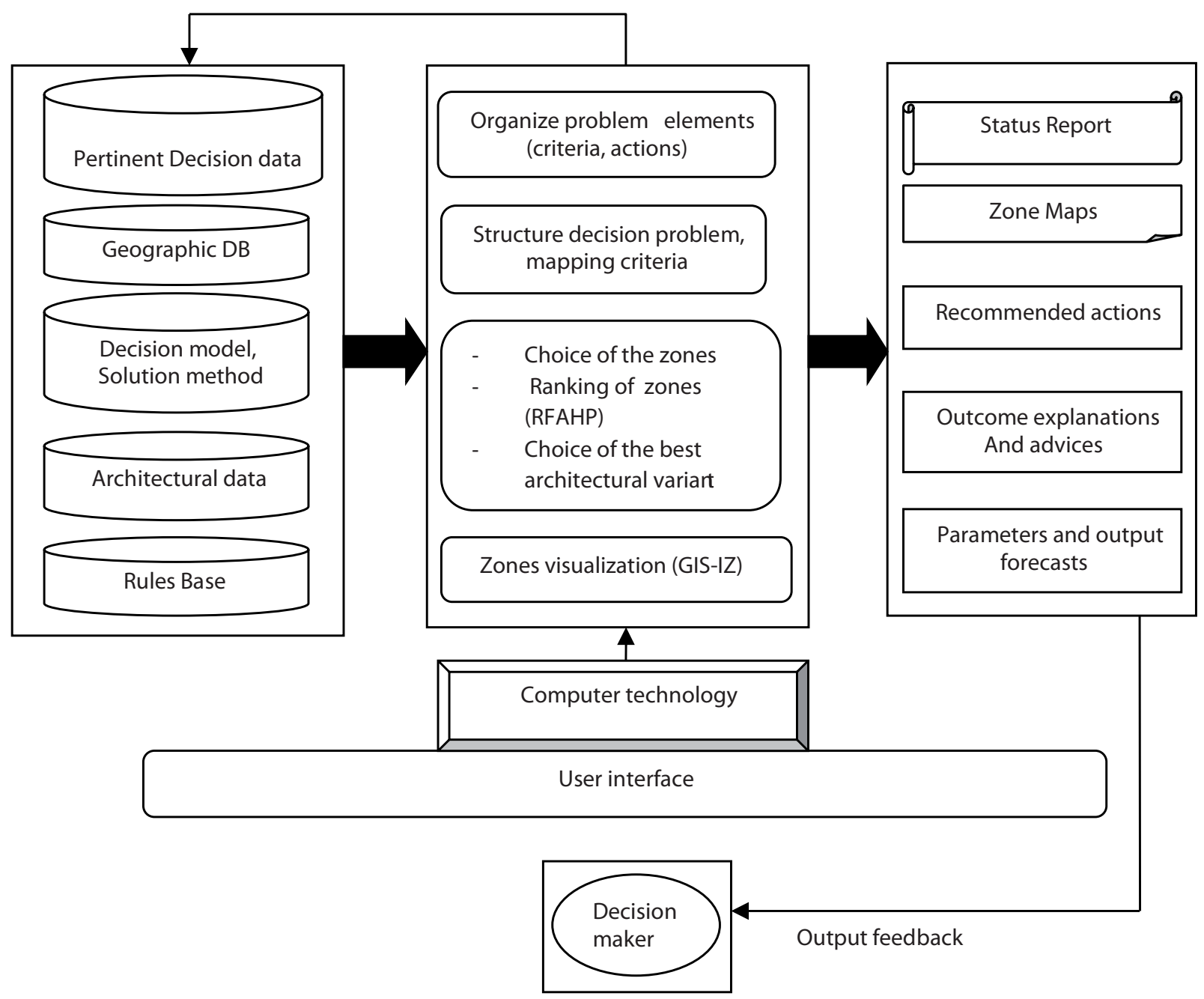

Fig. 5. General Spatial Decision Support System Architecture. 
DMSS Inputs: include a database of pertinent decision data, a geographic database for actions and criteria, a rule base and an appropriate method (AHP in this case).The decision maker utilizes computer technology via a user interface to access at various bases or executes the processing.

DMSS Processing: Process in three phases:

First phase: It is the phase of determining the aptitude of candidate zones in different regions. Zonal aptitude is defined by the properties of an area to satisfy pre-established conditions or to be favorable to the development of a given phenomenon [6].

The Boolean zoning is a multi-criteria decision-making approach using a single logic operator $(\cap)$ to combine the criteria for selecting zones, for example the aptitude binary index $C_{\text {slope }, j}$ for a zone $\mathrm{j}$ according to the slope criterion is given such that:

$$
\text { If } C_{\text {slope }, j} \leq 20^{\circ} \text { Then } 1 \text {, else } 0 \text {. }
$$

The aptitude of a zone is calculated using the intersection of all aptitude criteria binary values such that:

$$
I_{a p t, j}=C_{1, j} \cap C_{2, J} \cap \ldots \cap C_{k, j}
$$

$C_{k, j}$ is the aptitude binary value of the zone $\mathrm{j}$ according to the criterion $\mathrm{k}$.

Second phase (Aim of this paper): It is the total ranking of zones using conjointly decision rules and RFAHP (Ranking FAHP) unit to develop a ranking for zones.

Decision rules set specified for this case is used to reduce the number of criteria, this reduction improves results, reduces the complexity and decreases inconsistencies. Technical criteria allowing the use of an objective expertise are reduced using a set of adequate rules; we have in result, criteria with subjective importance whose values are derived by decision rules. After this step FAHP deals with reduced subjective criteria only.

Third phase: Consists to choose one of three available architectural variants, the selection criteria are: architecture, management cost, number of fragmented islands and the types of planned investments.

GIS-IZ module ensures the display of zones before and after each decision-making phase. To accomplish this task the vector mode is adopted, each industrial zone is considered as a geographical entity of the abstract spatial type "POINT", it is implemented with their geographical position (latitude and longitude) using Geo-Tools in three steps:

1. Introduce the file with shape file (SHP) extension, which represents the Algerian administrative division map.

2. Insert another file with the same extension representing industrial zones.

3. Make a projection between the two thematic maps.

DMSS Outputs: GIS-IZ unit displays the zones with their corresponding ranks on the map of Algeria as in Fig.6.

\section{Case Study}

Industrial zones under study are programmed by the Algerian state in 2013 to satisfy the expectations of investors. The objective is to reach the economic regional balance and population stabilization with respect to environment [44].

\section{A. Actions}

Industrial zones (Actions) under study are: Action1 (A1): SBA, Action2 (A2): Horchaia, Action3 (A3): Ras Elma, Action4 (A4): Maghnia, Action5 (A5): Kolea.

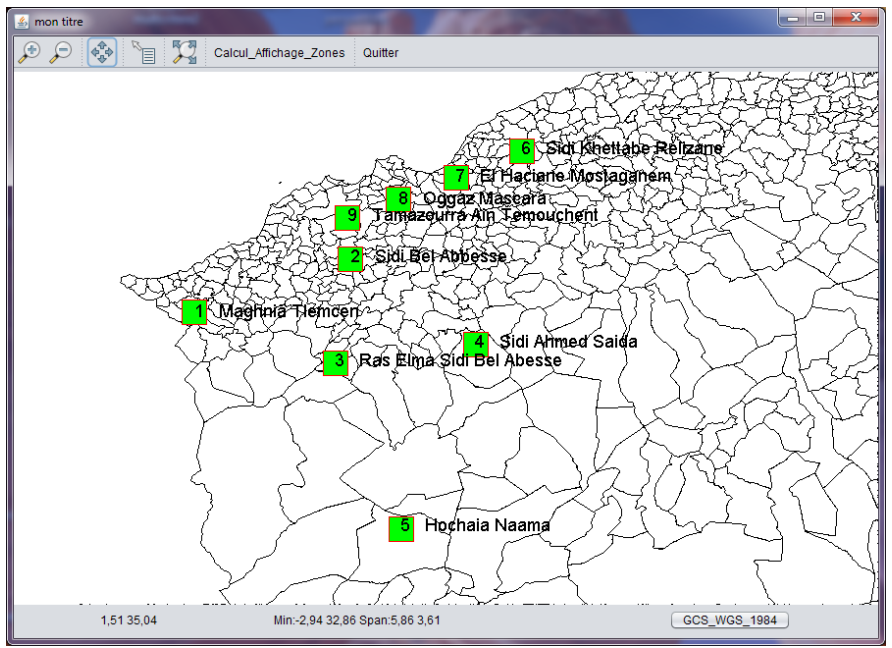

Fig. 6. Main visualizing interface.

\section{B. Criteria}

Criteria used in this study are classified into four categories:

Natural risk (Cr1), Socio-economic (Cr2), Environmental impact (Cr3) and Climate characteristics $\mathrm{Cr} 4$ ). According to these categories, 11 different evaluation criteria are defined. Fig. 7 shows the hierarchical structure of this problem according to the first step of AHP.

(Cr11): Risk groundwater pollution.

(Cr12): fauna and flora problem.

(Cr13): Citizens noises.

(Cr21): Seismicity.

(Cr22): Flood.

(Cr31): Temperature.

(Cr32): Rainfall.

(Cr33): bioclimatic Floor.

(C41): Cost management.

(Cr42): Equipment and development potentiality.

(Cr43): Transport Infrastructure.

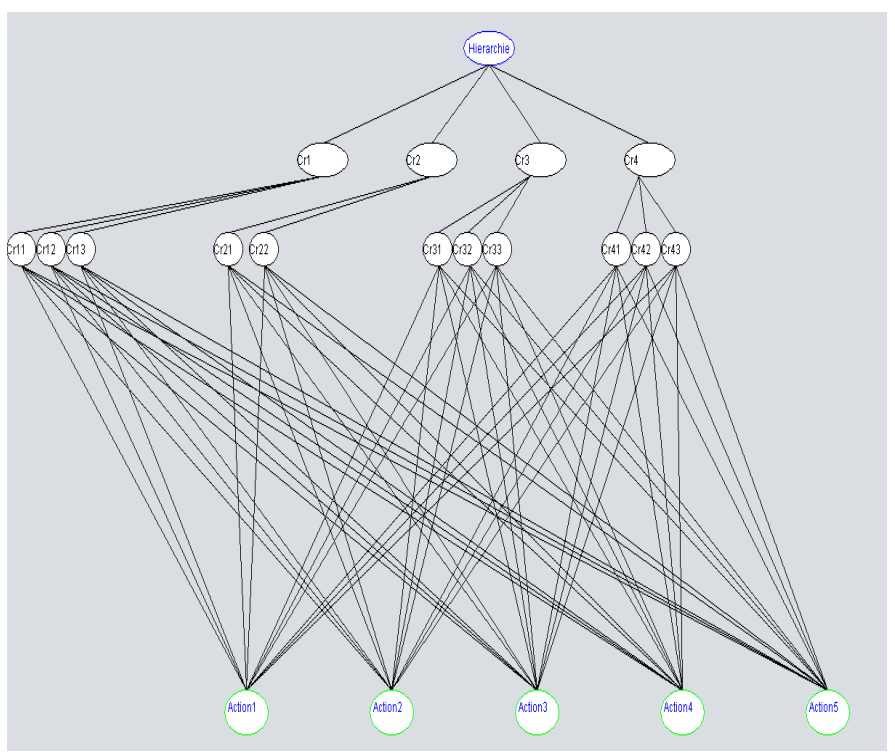

Fig. 7. Representation of the hierarchical structure, source (our SDMSS). 


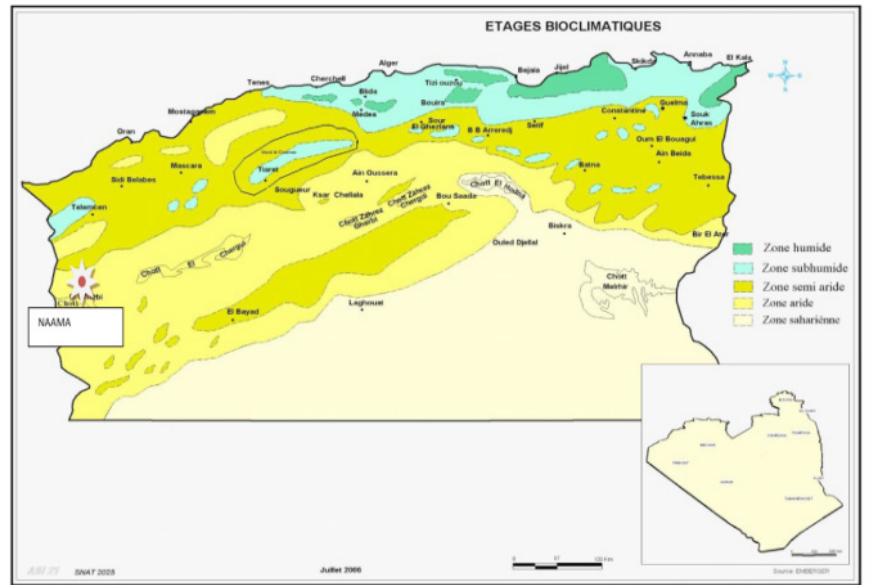

Fig. 8. Representation of bioclimatic floors of Algeria [44].

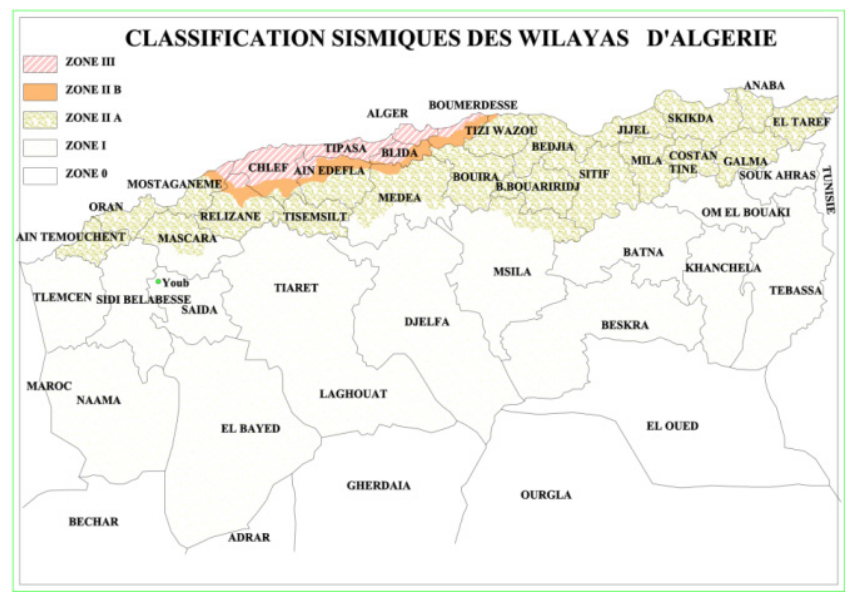

Fig. 9. Representation of seismic classification of Algeria.

\section{Rule base}

Rule base must be developed by experts since the deductions must be based on the field expertise. Problems encountered during development of this rule base are:

- High number of rules is necessary when tackling this problem, especially when the criteria number is elevated.

- There is a lot of possible criteria value in premises rules.

- Difficulty of ensuring, maintenance, coherence and completeness of the rule base.

To overtake these problems, more general rules are considered and when modeling rules premises, interval values are used instead of simple values if it is possible. Below the list of rules used in this study:

1. Rules set according to environmental impacts

\section{Rules structure:}

In conclusion rules, environmental impact $(\mathrm{Cr} 1)$ can be strong, low or moderate.

Premises rules contain a combination of the following criteria values:

(Cr11): Risk groundwater pollution (present, absent) (Cr12): Fauna and flora problem (existent, inexistent) (Cr13): Noise Citizen (strong, low)

Proposed rules:

R1: If $(\mathrm{Cr} 11=$ present $)$ and $(\mathrm{Cr} 12=$ exist $)$ and $(\mathrm{Cr} 13=$ strong) Then $\mathrm{Cr} 1=$ strong.

R2: If $(\mathrm{Cr} 11=$ present $)$ and $(\mathrm{Cr} 12=$ inexistent $)$ and $(\mathrm{Cr} 13=$ strong) Then $\mathrm{Cr} 1=$ strong.
R3: If $(\mathrm{Cr} 1=$ absent $)$ and $(\mathrm{Cr} 2=$ inexistent $)$ and $(\mathrm{Cr} 3=$ low $)$ Then $\mathrm{Cr} 1=$ low.

In other cases, $\mathrm{Cr} 1=$ moderate.

2. Rules set according to natural risks.

Rules structure:

In conclusion rules, natural risks $(\mathrm{Cr} 2)$ can be strong, low or moderate.

Premises rule contains a combination of the following criteria values:

(Cr21): Seismicity (low to moderate, low, strong)

(Cr22): Flood (low, moderate, strong)

Proposed rules:

$\mathrm{R} 1$ : If $(\mathrm{Cr} 21=$ low to moderate $)$ and $(\mathrm{Cr} 22=$ moderate $)$

Then $\mathrm{Cr} 2=$ moderate.

$\mathrm{R} 2$ : If $(\mathrm{Cr} 21=$ strong $)$ and $(\mathrm{Cr} 22=$ strong $)$

Then $\mathrm{Cr} 2=$ strong.

R3: If $(\mathrm{Cr} 21=$ strong $)$ and $(\mathrm{Cr} 22=$ moderate $)$

Then $\mathrm{Cr} 2=$ strong.

R4: IF $(\mathrm{Cr} 21=$ strong $)$ and $(\mathrm{Cr} 22=$ low to moderate $)$ Then $\mathrm{Cr} 2=$ strong.

R5: If $(\mathrm{Cr} 21=$ low and $\mathrm{Cr} 22=$ low to moderate $)$ Then $\mathrm{Cr} 2=$ moderate.

In other case, $\mathrm{Cr} 2=$ moderate.

3. Rules set according to climate characteristics

Rules structure:

In conclusion rules, climate characteristics $(\mathrm{Cr} 3)$ can be favorable, unfavorable or little favorable.

Premises rules contain a combination of the following criteria values:

(Cr31): Temperature (numeric values)

(Cr32): Rainfall (numeric values interval)

(Cr33): Bioclimatic floor (Arid, Semi Arid).

Proposed rules:

R1: If $(15<\mathrm{Cr} 31<20)$ and $(50<\mathrm{Cr} 32<200)$ and $(\mathrm{Cr} 33=$ semi arid $)$ Then $\mathrm{Cr} 3=$ favorable.

R2: If $(15<\mathrm{Cr} 31<40)$ and $(\mathrm{Cr} 32<400)$ and $(\mathrm{Cr} 33=$ semi arid $)$ Then $\mathrm{Cr} 3$ = favorable.

R3: If $(\mathrm{Cr} 31<10)$ Then $\mathrm{Cr} 3=$ unfavorable.

R4: If $(\mathrm{Cr} 31>50)$ Then $\mathrm{Cr} 3$ unfavorable.

In other cases, $\mathrm{Cr} 3=$ little favorable

4. Rules set according to socio-economic criterion

Rules structure:

In conclusion rules, socio economic criterion $(\mathrm{Cr} 4)$ can be very favorable, favorable, little favorable or unfavorable.

Premises rules contain a combination of the following criteria values:

(Cr41): Managing fee (numeric values)

(Cr42): Development potentiality (encouraging, not encouraging, little encouraging).

(Cr43):Transport Infrastructure (available, few available, unavailable)

Proposed rules:

R1: If $(\mathrm{Cr} 41>3 \mathrm{E}+9)$ and $(\mathrm{Cr} 42=$ not encouraging $)(\mathrm{Cr} 43=$

Few available) Then $\mathrm{Cr} 4=$ unfavorable. 
R2: If $(\mathrm{Cr} 41>3 \mathrm{E}+9)$ and $(\mathrm{Cr} 42=$ encouraging $)$ and $(\mathrm{Cr} 43=$ few available) Then $\mathrm{Cr} 4=$ few favorable.

R3: If $(\mathrm{Cr} 41>3 \mathrm{E}+9)$ and $(\mathrm{Cr} 42=$ encouraging $)$ and $(\mathrm{Cr} 43=$ available) Then $\mathrm{Cr} 4=$ favorable.

R4: If $(15 \mathrm{E}+8<\mathrm{Cr} 41<3 \mathrm{E}+9)$ and $(\mathrm{Cr} 42=$ encouraging $)$ and $(\mathrm{Cr} 43=$ few available $)$ Then $\mathrm{Cr} 4=$ favorable

R5: If $(\mathrm{Cr} 41<15 \mathrm{E}+8)$ and $(\mathrm{Cr} 42=$ encouraging $)$ and $(\mathrm{Cr} 43=$ available) $\mathrm{Then} \mathrm{Cr} 4=$ very favorable.

R6: If $(\mathrm{Cr} 41<15 \mathrm{E}+8)$ and $(\mathrm{Cr} 42=$ not encouraging $)$ and (Cr43 = unavailable) Then $\mathrm{Cr} 4=$ not favorable.

R7: If $(\mathrm{Cr} 41<1 \mathrm{E}+9)$ and $(\mathrm{Cr} 42=$ not encouraging $)$ and $(\mathrm{Cr} 43=$ available $)$ Then $\mathrm{Cr} 4=$ very favorable.

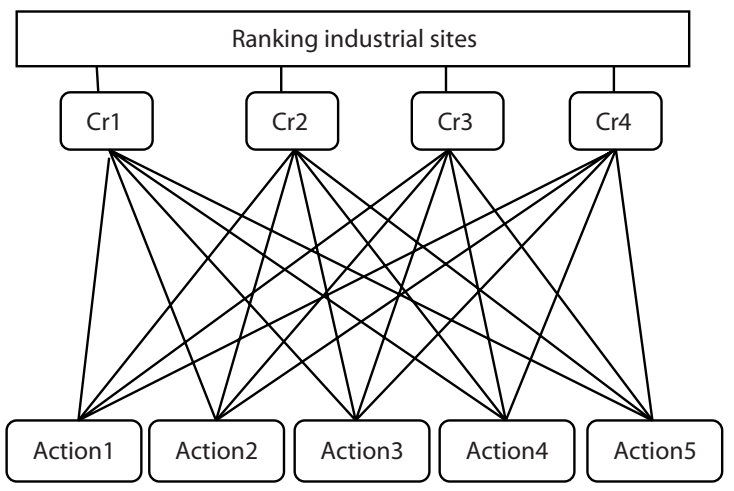

Fig. 10. The hierarchy structure after reduction.

\section{Pair Wise Comparisons Matrices}

All associated elements in the low hierarchy of each element in the tree structure are pairwise compared according to decision maker (DM's) opinion and Saaty 9-unit scale in Table I. Obtained matrices are transformed into fuzzy ones using the scale in Table II. Computing the normalized value of row sums (i.e. fuzzy synthetic extent) is done by fuzzy arithmetic operations. The pairwise comparison matrix for main criteria is given in Table III.

TABLE III. Pairwise Comparisons Between Main Criteria Based on the DM's OPINION.

\begin{tabular}{ccccc}
\hline \hline Criterion & $\begin{array}{c}\text { Env-impact } \\
\text { (Cr1) }\end{array}$ & $\begin{array}{c}\text { Nat-risk } \\
(\mathbf{C r 2})\end{array}$ & $\begin{array}{c}\text { Climate } \\
\text { (Cr3) }\end{array}$ & $\begin{array}{c}\text { Soc-eco } \\
\text { (Cr4) }\end{array}$ \\
\hline Env-impact(Cr1) & 1 & 5 & 3 & $1 / 3$ \\
Nat-risk(Cr2) & $1 / 5$ & 1 & $1 / 3$ & $1 / 7$ \\
Climate(Cr3) & $1 / 3$ & 3 & 1 & 5 \\
Soc-eco(Cr4) & 3 & 7 & $1 / 5$ & 1 \\
Total & 4,53 & 16 & 4,53 & 6.47 \\
\hline \hline
\end{tabular}

The fuzzy pairwise comparisons for main criteria are illustrated in Table IV.

TABLE IV. Fuzzy PAIRwise COMPARISONS For MAIN CRITERIA.

\begin{tabular}{ccccc}
\hline \hline Criterion & $\begin{array}{c}\text { Env-impact } \\
\text { (Cr1) }\end{array}$ & $\begin{array}{c}\text { Nat-risk } \\
\text { (Cr2) }\end{array}$ & $\begin{array}{c}\text { Climate } \\
\text { (Cr3) }\end{array}$ & $\begin{array}{c}\text { Soc-eco } \\
\text { (Cr4) }\end{array}$ \\
\hline Env-impact(Cr1) & $(1,1,1)$ & $(2,5,7)$ & $(1,3,5)$ & $(1 / 5,1 / 3,1 / 2)$ \\
Nat-risk(Cr2) & $(1 / 7,1 / 5,1 / 3)$ & $(1,1,1)$ & $(1 / 5,1 / 3,1 / 2)$ & $(1 / 9,1 / 7,1 / 5)$ \\
Climate(Cr3) & $(1 / 5,1 / 3,1 / 2)$ & $(2,3,5)$ & $(1,1,1)$ & $(3,5,7)$ \\
Soc-eco(Cr4) & $(2,3,5)$ & $(5,7,9)$ & $(1 / 7,1 / 5,1 / 3)$ & $(1,1,1)$ \\
Total & $(1,1,1)$ & $(2,5,7)$ & $(1,3,5)$ & $(1 / 5,1 / 3,1 / 2)$ \\
\hline
\end{tabular}

The values of fuzzy synthetic extent are evaluated using Eq. 1-6 as follows:

$$
\begin{gathered}
\sum_{j=1}^{m} M_{g_{i}}^{j}=\left(\begin{array}{c}
(4.2 ; 9.33 ; 13.5) \\
(1.45 ; 1.67 ; 2.03) \\
(6.2 ; 9.33 ; 13.5) \\
(8.14 ; 11.2 ; 15.33)
\end{array}\right) \\
S_{i}=\left[\begin{array}{ccc}
\frac{4.2}{44.26} & \frac{9.33}{31.53} & \frac{13.5}{20} \\
\frac{1.45}{44.26} & \frac{1.67}{31.53} & \frac{2.03}{20} \\
\frac{6.2}{44.26} & \frac{9.33}{31.53} & \frac{13.5}{20} \\
\frac{8.14}{44.26} & \frac{11.2}{31.53} & \frac{15.33}{20}
\end{array}\right]=\left[\begin{array}{ccc}
0.095 & 0.3 & 0.67 \\
0.03 & 0.053 & 0,10 \\
0.14 & 0.3 & 0.67 \\
0.18 & 0.35 & 0.76
\end{array}\right]
\end{gathered}
$$

The last step is devoted to converting fuzzy values into crisp ones. It is done by applying the average function which is adequate with the attitude of the decision maker. Fuzzy weights and their corresponding crisp weights are illustrated in Table V.

TABLE V. Weight Calculating for Main Criteria

\begin{tabular}{ccccc}
\hline \hline Criterion & \multicolumn{3}{c}{ Fuzzy weight } & Crisp weight \\
\hline Env-impact(Cr1) & 0.095 & 0.3 & 0.67 & 0.355 \\
Nat-risk(Cr2) & 0.03 & 0.053 & 0.10 & 0.061 \\
Climate(Cr3) & 0.14 & 0.3 & 0.67 & 0.37 \\
Soc-eco(Cr4) & 0.18 & 0.35 & 0.76 & 0.43 \\
\hline
\end{tabular}

The fuzzy pairwise comparisons for alternatives over all criteria are illustrated in Table VI.

TABLE VI.

\begin{tabular}{|c|c|c|c|c|c|}
\hline Cr1 & A1 & A2 & $\mathbf{A 3}$ & A4 & A5 \\
\hline A1 & $(1,1,1)$ & $(1,3,5)$ & $(1 / 6,1 / 4,1 / 2)$ & $(1 / 5,1 / 3,1)$ & $(1 / 9,1 / 7,1 / 5)$ \\
\hline A2 & $(1 / 5,1 / 3,1)$ & $(1,1,1)$ & $(1,3,5)$ & $(1 / 7,1 / 5,1 / 3)$ & $(3,5,7)$ \\
\hline A3 & $(2,4$, & $(1 / 5,1$ & & $(1 / 9,1 /$ & $(3,5,7)$ \\
\hline A4 & $(1,3,5$ & $(3,5,7)$ & $(5,7,9)$ & $(1,1,1)$ & $(1,2,4)$ \\
\hline A5 & $(5,7$, & $(1 / 7,1 / 5,1 / 3)$ & $(1 / 7,1 / 5,1 / 3)$ & $(1 / 4,1 /$ & $(1,1,1)$ \\
\hline Cr2 & A1 & A1 & A1 & A1 & A1 \\
\hline A1 & $(1,1,1$ & $(1 / 4,1 / 2$ & $(1 / 5,1 / 3$ & $(1 / 5,1 / 3$ & $(2,4,6)$ \\
\hline A2 & $(1,2,4)$ & $(1$, & $(1 / 5,1 / 3,1)$ & $(1 / 5,1)$ & $(1 / 4,1 / 2,1)$ \\
\hline A3 & $(1,3$ & $(1$, & $(1,1,1)$ & $(1 / 6,1 / 2$ & $(1,3,5)$ \\
\hline A4 & $(1,3$ & & $(2,4$ & & $(1,3,5)$ \\
\hline A5 & $(1 / 6,1 / 4,1$ & $(1,2$ & $(1 / 5,1 / 3$ & $1 / 5,1$ & $(1,1,1)$ \\
\hline $\mathrm{Cr} 3$ & A1 & A1 & A1 & A1 & A1 \\
\hline A1 & $(1,1$, & $(1,3$ & $(3,5,7$ & $(1,3$ & $(1 / 4,1 / 2,1)$ \\
\hline A2 & $(1 / 5,1)$ & $(1$, & $(1 / 4,1 / 2,1)$ & $(2,4$ & $(1 / 5,1 / 3,1)$ \\
\hline $\mathbf{A 3}$ & $(1 / 7,1 / 5$ & $(1,2$ & $(1,1$ & $(1 / 9,1 / 7,1 / 5)$ & $(1 / 5,1 / 3,1)$ \\
\hline A4 & $(1 / 5,1 / 3,1)$ & $(1 / 6,1 / 4,1 / 2)$ & $(5,7,9)$ & $(1,1,1)$ & $(1 / 5,1 / 3,1)$ \\
\hline A5 & $(1,2,4)$ & $(1,3,5)$ & $(1,3,5)$ & $(1,3,5)$ & $(1,1,1)$ \\
\hline Cr4 & A1 & & A & & A1 \\
\hline A1 & $(1,1,1$ & (3, & $(4,6,8$ & $(1 / 7,1 / 5,1 / 3$ & $(1 / 5,1 / 3,1)$ \\
\hline A2 & $(1 / 7,1 / 5$ & $(1,1,1)$ & $(1 / 7,1 / 5,1 / 3)$ & $(1,2,4)$ & $(5,7,9)$ \\
\hline A3 & $(1 / 8,1 / 6,1 / 4)$ & $(3,5,7)$ & $(1,1,1)$ & $(1,3,5)$ & $(1 / 6,1 / 4,1 / 2)$ \\
\hline A4 & $(3,5$, & $(1 / 4,1 / 2$ & $(1 / 5,1 / 3,1 / 2)$ & $(1,1,1)$ & $(1 / 7,1 / 5,1 / 3)$ \\
\hline A5 & $(1,3,5)$ & $(1 / 9,1 / 7,1 / 5)$ & $(2,4,6)$ & $(3,5,7)$ & $(1,1,1)$ \\
\hline
\end{tabular}

Fuzzy Pairwise Comparison Matrix for Alternatives Over Criteria

The priority calculating of alternatives over the different criteria are illustrated in Table VII.

To calculate the final rank of each action $\mathrm{A}_{\mathrm{i}}(\mathrm{i}=1 \ldots 5)$ we consider all paths that link each action with the goal in the graph of the hierarchy (Fig. 10.) according to the following formula:

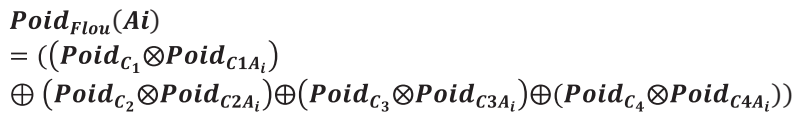


TABLE VII. Weights AND RANKS FOR the Alternatives over CRiteria

\begin{tabular}{|c|c|c|c|c|c|}
\hline Cr1 & \multicolumn{3}{|c|}{ Fuzzy weight } & Crisp weight & Rank \\
\hline A1 & 0.032 & 0.091 & 0.243 & 0.122 & 5 \\
\hline A2 & 0.0713 & 0.184 & 0.45 & 0.235 & 4 \\
\hline A3 & 0.084 & 0.2 & 0.48 & 0.25 & 3 \\
\hline A4 & 0.147 & 0.34 & 0.82 & 0.43 & 1 \\
\hline A5 & 0.0872 & 0.34 & 0.36 & 0.26 & 2 \\
\hline Cr2 & \multicolumn{3}{|c|}{ Fuzzy weight } & Crisp weight & Rank \\
\hline A1 & 0.11 & 0.16 & 0.44 & 0.23 & 3 \\
\hline A2 & 0.041 & 0.10 & 0.35 & 0.1636 & 4 \\
\hline A3 & 0.065 & 0.26 & 0.73 & 0.3516 & 2 \\
\hline A4 & 0.093 & 0.36 & 0.97 & 0.47 & 1 \\
\hline A5 & 0.04 & 0.10 & 0.33 & 0.156 & 5 \\
\hline Cr3 & \multicolumn{3}{|c|}{ Fuzzy weight } & Crisp weight & Rank \\
\hline A1 & 0.092 & 0.29 & 0.795 & 0.3923 & 1 \\
\hline A2 & 0.053 & 0.14 & 0.42 & 0.20 & 4 \\
\hline A3 & 0.036 & 0.08 & 0.27 & 0.13 & 5 \\
\hline A4 & 0.096 & 0.20 & 0.52 & 0.272 & 3 \\
\hline A5 & 0.0735 & 0.27 & 0.83 & 0.3911 & 2 \\
\hline $\mathrm{Cr} 4$ & \multicolumn{3}{|c|}{ Fuzzy weight } & Crisp weight & Rank \\
\hline A1 & 0.11 & 0.20 & 0.53 & 0.28 & 2 \\
\hline A2 & 0.097 & 0.17 & 0.45 & 0.24 & 3 \\
\hline A3 & 0.07 & 0.153 & 0.42 & 0.214 & 4 \\
\hline A4 & 0.06 & 0.11 & 0.30 & 0.1566 & 5 \\
\hline A5 & 0.095 & 0.21 & 0.588 & 0.297 & 1 \\
\hline
\end{tabular}

For example, the result fuzzy weight, crisp weight and rank of $A_{1}$ (SBA) is calculated such that:

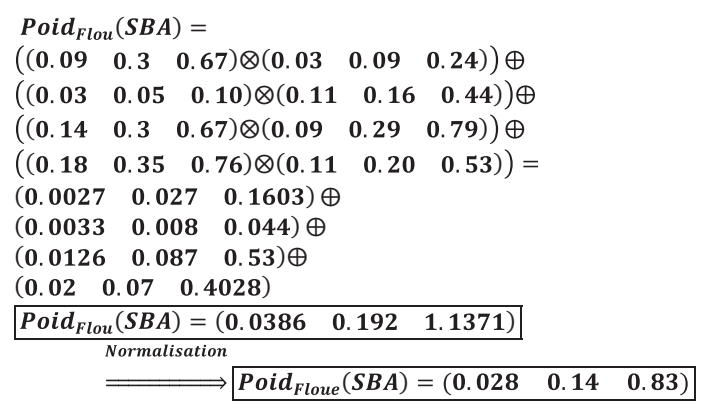

In the same way we calculate the weights and consequently the ranks of the actions $\mathrm{A}_{2}, \mathrm{~A}_{3}, \mathrm{~A}_{4}$ and $\mathrm{A}_{5}$.

Obtained ranks of zones according to our approach are illustrated in Table VIII.

TABLE VIII

The Final Ranks For the Actions (ObTained by AHP and FAHP).

\begin{tabular}{ccccccc}
\hline Industrial zones & $\begin{array}{c}\text { AHP } \\
\text { Weights (\%) }\end{array}$ & $\begin{array}{c}\text { AHP } \\
\text { Ranks }\end{array}$ & \multicolumn{2}{c}{ FAHP Weights (\%) } & $\begin{array}{c}\text { FAHP } \\
\text { Ranks }\end{array}$ \\
\hline SBA (A1) & 21.4 & 3 & 2 & 14 & 83 & 3 \\
Hourchia (A2) & 17.02 & 4 & 3 & 16 & 95 & 1 \\
Koléa (A3) & 11.38 & 5 & 2 & 14 & 89 & 2 \\
Ras Elma (A4) & 25.7 & 1 & 2 & 14 & 82 & 5 \\
Maghnia (A5) & 21.50 & 2 & 2 & 16 & 81 & 4 \\
\hline \hline
\end{tabular}

\section{CONCLUSION}

This paper proposes an approach based on the FAHP, GIS and Decision rules for ranking industrial sites in Algeria. The process of decision-making consists of a two-stage analysis:

An initial site screening followed by a detailed assessment of the suitability candidate sites. Because the human decision-making process usually contains fuzziness and vagueness, the FAHP is used to overcome this problem. GIS is used to prepare geographic data in screening phase and to visualize ranked zones on a map in the evaluation phase. Because it is advantageous to combine the MCDA techniques with rule base, a set of rules is utilized and serves as a filter that performs a pre-treatment of criteria and consequently reduces the problem complexity. In terms of complexity we save to build $11 \times(5 \times 5)$ matrixes with their fuzzy extent and priority calculating in this case. This research allowed us to determine the usefulness of the approach study for a site selection sector where the decision is important and dangerous, and intersects with the geography and even history. The rank of an industrial zone so obtained is an index with which we can:

- Criticize the choice of zones.

- Alert the planners and builders of zones.

- Assign the zone to adequate investment projects.

As a future direction we will engage Data Mining for the construction of the rule base. The conjunctive rules obtained after learning will be used for reduction criteria by exploiting the transition functions of the cellular machine CASI (Cellular Automation for Symbolic Induction). In response to the limitations of various approaches to rules simplifications, we use CASI, which makes it possible to eliminate redundant and incoherent information in order to produce an optimal set of rules $[46,47]$.

\section{REFERENCES}

[1] Khalid, E., "Exploring multi-criteria decision strategies in GIS with linguistic quantifiers: An extension of the Analytical Network Process using Ordered Weighted Averaging operators", International Journal of Geographical Information Science, 815356, 2013.

[2] D. Magaña Martínez and J.C. Fernández Rodríguez, "Artificial Intelligence applied to project success: a literature review", International Journal of Artificial Intelligence and Interactive Multimedia, Vol. 3, No.5, PP. 77-82, 2015.

[3] R. M. Dawes, "The Robust Beauty of Improper Linear Models in Decision Making”, American psychologist, Vol. 34, No. 7, PP. 571-582, 1979.

[4] R. Balzarini, P.-A. Davoine, and M. Ney, "Evolution et développement des méthodes d'Analyse spatiale multicritère pour des modèles d'aptitude : L'exemple des applications en Géosciences", presented at Conférence Francophone ESRI, Oct. 2011, Versailles, France.

[5] Chakhar, S., "Cartographie Décisionnelle Multicritère : Formalisation Et Implémentation Informatique ", Thèse de doctorat, D.F.R. Sciences des Organisations, Université Paris Dauphine, France,2006.

[6] R. Caloz and C. Collet, Analyse spatiale de l'information géographique, Presse polytechniques et universitaires romandes, 2011.

[7] Y.-M. Wang, Y. Luo and Z. Hua, "On the extent analysis method for fuzzy AHP and its applications", European Journal of Operational Research, PP.735-747, 2008.

[8] M.H. Vahidniaa, A. Alesheikhb, A. Alimohammadic and A. Bassirid, "A Fuzzy Analytical Hierarchy Process in GIS Application", the International Archives of the Photogrammetry, Remote Sensing and Spatial Information Sciences. Vol.37.part B2. Beijing, 2008.

[9] T. L. Saaty, "Decision making with the analytic hierarchy process", Int. J. Services Sciences, Vol. 1, No. 1, PP.83-98, 2008.

[10] Y. Ge, Q. Xu and H. Li, "The Design and Application of a Generic AHP Evaluation System", in Proc. 4th International Conference on Wireless Communications, Networking and Mobile Computing, Dalian. China, 2008, PP 248-252.

[11] D.Y. Chang, "Applications of the extent analysis method on fuzzy AHP", European Journal of Operational Research, 95, PP. 649-655, 1996.

[12] Malczewski, J., "GIS-based multi-criteria decision analysis: a survey of the literature", International Journal of Geographical Information Science, Vol. 20, No. 7, PP. 703-726, 2006.

[13] Musakwa, W., Makoni. E. N., Kangethe, M. and Segooa L., "Developing a decision support system to identify strategically located land for land reform in south Africa", the International Archives of the Photogrammetry, Remote Sensing and Spatial Information Sciences, Vol. XL, No.1-3, PP. 
196-203, 2014.

[14] Karim, L., "On the motivation behind MCDA and GIS integration", Int. J. Multicriteria Decision Making, Vol. 3, No. 2/3, PP. 101-113, 2013.

[15] Joerin, F., Thériault, M. and Musy, A., "Using GIS and outranking multicriteria analysis for land-use suitability assessment", International Journal of Geographical Information Science, Vol. 15, No. 2, PP. 153-174, 2001.

[16] Khalid, E., "A COM-based Spatial Decision Support for Industrial Site Selection", Journal of Geographic Information and Decision Analysis, Vol. 7, No. 2, PP. 72 - 92, 2003.

[17] A. Rikalovic, I. Cosic, and D. Lazarevic, "GIS Based Multi-Criteria Analysis for Industrial Site Selection", in Proc.24th DAAAM International Symposium on Intelligent Manufacturing and Automation, 2013, PP. 1054-1063.

[18] V. Ferreti, "Integrating Multicriteria Analysis and Geographic Information Systems for studying ecological corridors in the Piedmont Region", presented at the 74th Meeting of the European Working Group, Multiple Criteria Decision Aiding.

[19] G. Massei, L. Rocchi, L. Paolotti, S. Greco and A. Boggia, "Decision Support Systems for environmental management: A case study on wastewater from agriculture", Journal of Environmental Management Vol. 14, No.6, PP. 491-504, 2014.

[20] M. Anane, H. Kallali and S. Jellali, "Ranking suitable sites for Soil Aquifer Treatment in Jerba Island (Tunisia) using remote sensing, GIS and AHPmulticriteria decision analysis", Int. J. Water, Vol. 4, Nos. 1/2, 2008.

[21] C. Prévil, M. Thériault and J. Rouffignat, "Analyse multicritère et SIG pour faciliter la concertation en aménagement du territoire : vers une amélioration du processus décisionnel", Les Cahiers de géographie du Québec, Vol. 47, No. 130, PP. 35-61, 2003.

[22] M.L. Vazquez, J.-P. Waaub, A. Ilinca and J.-L. Chaumel, “Analyse spatiale et approche d'aide multicritères et multi acteurs a la négociation pour évaluer des scenarios d'implantation des parcs éoliens", présenté a la $1^{\text {ere }}$ Conférence Intercontinentale d'Intelligence Territoriale «Interdisciplinarité dans l'aménagement et développement des territoires», PP.10, Oct. 2011, Gatineau, Canada.

[23] Dedemen, Y., "A multi-criteria decision analysis approach to GIS-based route selection for overhead power transmission lines", Thesis submitted to the Graduate School of Natural and Applied Sciences of Middle East Technical University. Department of Geodetic and Geographic Information Technologies, 2013.

[24] Y. Meng, J. Malczewski and S. Boroushaki, “A GIS-Based Multicriteria Decision Analysis Approach for Mapping Accessibility Patterns of Housing Development: A Case Study in Canmore, Alberta", Journal of Geographic Information System, Vol. 3, PP. 50-61, 2011.

[25] S. Kubler, J. Robert, W. Derigent, A. Voisin and Yves Le. Traon, “A stateof the art \& testbed of fuzzy AHP (FAHP) applications", Experts Systems with Application, Vol. 65, PP. 398-422, 2016.

[26] T. Rashed and J. Weeks, "Assessing vulnerability to earthquake hazards through spatial multicriteria analysis of urban areas", International Journal of Geographical Information Sciences, Francis and Taylor edition, 2003.

[27] E. H. Ibrahim, S. E. Mohamed, and A. A. Atwan, "Combining fuzzy analytic hierarchy process and GIS to select the best location for a wastewater lift station in Elmahalla El-kubra, North Egypt”, International Journal of Engineering \& Technology, Vol.11, No. 05, PP. 37-43, 2011.

[28] V. Akbari, M.A. Rajabi, S.H. Chavoshi and R. Shams, "Landfill Site Selection by Combining GIS and Fuzzy Multi Criteria Decision Analysis, Case Study: Bandar Abbas, Iran”, World Applied Sciences Journal, Vol. 3, PP. 39-47, 2008.

[29] S.-Y. Chou, Y.-H. Chang, C.-Y. Shen, “A fuzzy simple additive weighting system under group decision-making for facility location selection with objective/subjective attributes", European Journal of Operational Research, Vol. 189, PP.132-145, 2008.

[30] S. Sener, E. Sener, B. Nas and R. Karaguzel "Combining AHP with GIS for landfill site selection: A case study in the Lake Beys Ehircatchment area (Konya, Turkey)", Waste Management journal, Vol. 30, 2010.

[31] S. Sener, E. Sener and R. Karagüzel, "Solid waste disposal site selection with GIS and AHP methodology: a case study in Senirkent-Uluborlu (Isparta) Basin, Turkey”, Environ Monit Assess journal, 173, PP. 533-554, 2011.

[32] M. Ekmekciog lu, T. Kaya and C. Kahraman, "Fuzzy multicriteria disposal method and site selection for municipal solid waste", Waste Management journal Vol. 30, PP. 1729-1736, 2010.
[33] C.-C. Chou and K.-W. Yu , "Application of a New Hybrid Fuzzy AHP Model to the Location Choice", Hindawi Publishing Corporation Mathematical Problems in Engineering journal, Vol. 2013, Article ID 592138, 12 pages, 2013.

[34] T.-Y. Choua, C.-L. Hsu, and M.-C. Chen, "A fuzzy multi-criteria decision model for international tourist hotels location selection", International Journal of Hospitality Management, Vol. 27, PP. 293-301, 2008.

[35] M. Z. Naghadehi, R. Mikaeil and M. Ataei, "The application of fuzzy analytic hierarchy process (FAHP) approach to selection of optimum underground mining method for Jajarm Bauxite Mine, Iran", Expert Systems with Applications, Vol. 36, PP. 8218-8226, 2015.

[36] O. Boutkhoum, M. Hanine, T. Agouti and A. Tikniouine, "An improved hybrid multi-criteria multidimensional model for strategic industrial location selection: Casablanca industrial zones as a case study”. Springer Plus, 2015.

[37] W. Ho, "Integrated analytic hierarchy process and its applications - A literature review", European Journal of Operational Research, Vol. 186, PP. 211-228, 2008.

[38] R. Ramanathan, "A note on the use of the analytic hierarchy process for environmental impact", Assessment Journal of Environmental Management, Vol.63, PP. 27-35, 2001.

[39] Y.-C. Tang and M. J. Beynon, "Application and Development of a Fuzzy Analytic Hierarchy Process within a Capital Investment Study", Journal of Economics and Management, Vol. 1, No. 2, PP. 207-230, 2005.

[40] S. Greco, B. Matarazzo and R. Słowiński, "Decision rule approach", New York: Springer-Verlag, 2005, ch. 13 pp. 507-562.

[41] K. Frakling, "Modélisation et apprentissage des préférences par réseaux de neurones pour l'aide à la décision multicritère“. Thèse doctorat, Ecole nationale des mines de Saint-Etienne, 1996.

[42] A.H.I. Lee, W.-C. Chen and C.-J. Chang, "A fuzzy AHP and BSC approach for evaluating performance of IT department in the manufacturing industry in Taiwan", Expert Systems with Applications, Vol.34, PP.96-107, 2008.

[43] Guisseppi, A. and Forgionne, R. R., "Effective DMSS Guidance for Financial Investing", International Journal of Decision Support System Technology,(IJDSST), Vol.1, No. 1, PP. 1-14, 2009.

[44] ANIREF (Agence Nationale d'Intermédiation et de REgulation Fonciére), "Etude preliminaire d'amenagement du parc industriel", technical report, 2013, Alger, Algerie.

[45] A. Taibi, B. Atmani, "Multicriteria Decision Aided System for ranking industrial zones (RPRO4SIGZI)", in pro, The Fourth International Conference on Database and Data Mining (DBDM 2016). Dubai, UAE, April 23 24, 2016.

[46] Atmani, B., and Beldjilali, B., "Knowledge Discovery in Database: Induction Graph and Cellular Automaton", Computing and Informatics Journal, Vol.26, No. 2, PP. 171-197, 2007.

[47] Benfriha, H., Barigou, F. and Atmani, B., "A text categorization framework based on concept lattice and cellular automata", Int. J. of Data Science, Vol. 1, No.3, pp. 227 -246, 2016.

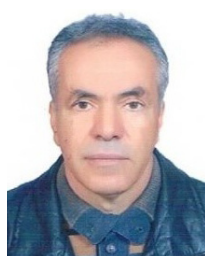

Taibi Aissa

He is a computer science teacher at the Faculty of Social Science of Oran2 University (Algeria). He earned his Master of Science degree in 2002 from Oran1 Ahmed Benbella University. He is currently a Ph.D. candidate in the Computer Science Department at the same university. His research interests focus on Multi-criteria decision analysis and geographic information systems, Expert Systems, social data analysis and fuzzy reasoning.

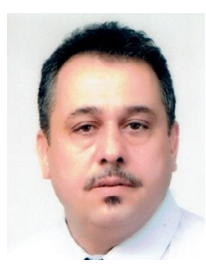

Baghdad Atmani

He is a Professor of Computer Science at the University of Oran 1 Ahmed Benbella. His field of interests is Data Mining and Machine Learning Tools. His research is based on Knowledge Representation, Knowledge-based Systems and CBR, Data and Information Integration and Modelling, Data Mining Algorithms, Expert Systems and Decision Support Systems. His research is guided and evaluated through various applications in the field of control systems, scheduling, production, maintenance information retrieval, simulation, data integration and spatial data mining. 